See Article page 80.

\section{Commentary: Pushing the boundaries? Robot-assisted excision of mitral annular calcification}

\author{
Anelechi C. Anyanwu, MD, Aarti Patil, MD, and \\ David H. Adams, MD
}

Robotic mitral valve repair and radical resection of mitral annular calcification (MAC) independently require a high degree of technical skill. Loulmet and colleagues ${ }^{1}$ describe a remarkable series of 64 patients undergoing robotic mitral valve repair and concurrent resection of MAC. The authors are to be applauded for this work. It goes without saying that theirs is an exceptionally skilled team in both robotic surgery and mitral valve surgery to reproducibly perform such complex surgery. This series demonstrates that this is an operation that can be done by a dedicated and highly advanced robotic surgical team. However, for the reader, the question these data pose is should it be done? Most surgeons have never performed a radical excision of MAC, and most surgeons do not perform mitral valve surgery with a robot. Should we now all learn how to (1) perform extensive resection of MAC, (2) do robotic mitral valve repair, and then (3) perform extensive resection of MAC with a robot? Is the authors' conclusion 'Successful en-bloc resection and complex reconstruction, utilizing a variety of techniques, can be consistently achieved with a robotic approach" generalizable to other centers? If others embarked on this procedure, would similar results be achieved "consistently"? It must be noted that there are no other large series of robotic excision of MAC from other

\footnotetext{
From the Department of Cardiovascular Surgery, Icahn School of Medicine at Mount Sinai, New York, NY.

Disclosures: The Icahn School of Medicine at Mount Sinai receives royalty payments from Edwards Lifesciences and Medtronic for intellectual property related to Dr Adams' involvement in the development of 2 mitral valve repair rings and 1 tricuspid valve repair ring. Dr Adams is the National Co-Principal Investigator of the CoreValve United States Pivotal Trial, which is supported by Medtronic. All other authors have nothing to disclose with regard to commercial support.

Received for publication Dec 23, 2019; revisions received Dec 23, 2019; accepted for publication Dec 24, 2019; available ahead of print Jan 22, 2020.

Address for reprints: Anelechi C. Anyanwu, MD, Department of Cardiovascular Surgery, Icahn School of Medicine at Mount Sinai, 1190 Fifth Ave, GP2W, Box 1028, New York, NY 10029 (E-mail: anelechi.anyanwu@mountsinai.org).

J Thorac Cardiovasc Surg 2021;161:93-4 $0022-5223 / \$ 36.00$

Copyright (c) 2020 Published by Elsevier Inc. on behalf of The American Association for Thoracic Surgery

https://doi.org/10.1016/j.jtcvs.2019.12.098
}

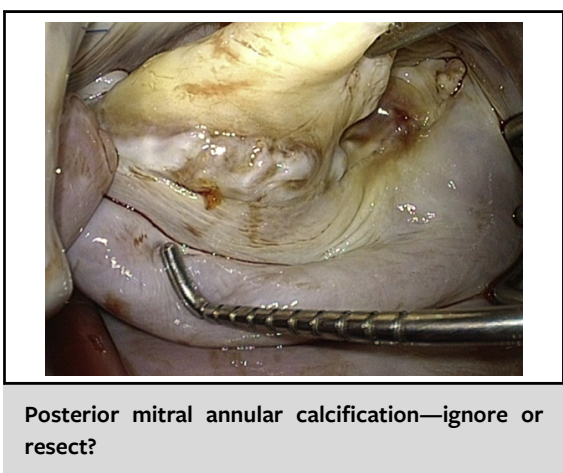

CENTRAL MESSAGE

Robotic excision of mitral annular calcification can be done by highly skilled surgical teams but is associated with increased morbidity. The everyday surgeon should consider simpler alternatives.

centers. Indeed, extensive MAC has generally been considered a contraindication to the robotic approach. ${ }^{2}$

Despite the authors' impressive $97 \%$ repair rate, robotic MAC resection did come at a price of incremental morbidity and risk. For example, authors reported greater rates of conversion to sternotomy $(4.7 \%$ vs $0.4 \%)$, return to operating room $(7.8 \%$ vs $1.8 \%)$, repeat mitral reintervention $(4.7 \%$ vs $0.4 \%)$, and 30-day mortality (3.1\% vs $0.2 \%$ ) compared with patients who underwent robotic surgery without MAC excision. Although the 2 groups may not be directly comparable, at least some complications may be explainable by the addition of MAC excision. In young or asymptomatic patients with MAC undergoing mitral valve repair, these incremental morbidity rates will challenge the benefits of early surgery. The question, therefore, arises as to the outcomes these patients would experience with alternative techniques. Loulmet and coworkers ${ }^{1}$ did not evaluate other approaches of MAC management, so we do not know what their outcomes would have been for patients treated with less-radical approaches. We have favored a more conservative "respect" approach to $\mathrm{MAC}^{3}$ and with that have experienced very low morbidity and mortality. ${ }^{4}$

Globally, patients undergoing robotic mitral valve surgery remain a highly selected patient population. Older patients, those with advanced disease, complex valve 
pathology, and those with more comorbidity are more likely to be referred and/or accepted for sternotomy compared with the robotic approach. Patients with MAC are, no doubt, complex, so what would be the expected benefit of the robotic over sternotomy approach in such cases? How do we counsel the patients? It is worth mentioning that there have been no consistently demonstrable benefits of robotic mitral valve repair in standard cases, other than better cosmesis, and possibly quicker early recovery. There is certainly no evidence that robotic repairs are superior to sternotomy in terms of safety, effectiveness, or durability-indeed, there may be indirect pointers that the opposite may be the case. These are important considerations, as the greater the risk and complexity of a procedure, the more that safety and effectiveness, as opposed to cosmesis and short-term recovery, should be the driving factors in choice of procedure. At least in majority of surgeons' hands (including most robotic surgeons), the sternotomy should, therefore, remain the default for the patient with MAC. This is truly a remarkable series demonstrating advanced surgical management by a highly focused 2-surgeon team working together on every case. Do watch the video and marvel at a demonstration that tests the extremes of technology, surgical skill, and surgical courage—-but please don't try this one at home!

\section{References}

1. Loulmet D, Ranganath NK, Neragi-Miandoab S, Koeckert MS, Galloway AC, Grossi EA. Advanced experience allows robotic mitral valve repair in the presence of extensive mitral annular calcification. J Thorac Cardiovasc Surg. 2021;161:80-8.

2. Gillinov AM, Suri R, Mick S, Mihaljevic T. Robotic mitral valve surgery: current limitations and future directions. Ann Cardiothorac Surg. 2016;5: 573-6.

3. El Eshmawi A, Alexis SL, Sengupta A, Pandis D, Rimsukcharoenchai C, Adams DH, et al. Surgical management of mitral annular calcification. Curr Opin Cardiol. 2020;35:107-15.

4. Castillo JG, Anyanwu AC, Fuster V, Adams DH. A near 100\% repair rate for mitral valve prolapse is achievable in a reference center: implications for future guidelines. J Thorac Cardiovasc Surg. 2012;144:308-12.
See Article page 80

\section{Commentary: Lessons from 1000 robotic mitral repairs}

\author{
Joanna Chikwe, MD, FRCS, Alfredo Trento, MD, \\ Wen Cheng, MD, Dominic Emerson, MD, and \\ Danny Ramzy, MD
}

In their analysis of 500 patients who underwent robotic mitral repair between 2011 and 2017, Loulmet and colleagues ${ }^{1}$ encountered significant mitral annular calcification (MAC) in 54 patients (12\%), which they addressed,

\footnotetext{
From the Department of Cardiac Surgery, Smidt Heart Institute, Cedars-Sinai Medical Center, Los Angeles, Calif.

Disclosures: Dr Trento participated on the steering committee of the design of the MitraClip (Abbott Laboratories). Dr Ramzy has received speaker honoraria, consulting fees, and/or educational grants from Abbott, Medtronic, LivaNova, and Abiomed and is a proctor for Intuitive and Livanova. Cedars-Sinai Medical Center receives honoraria from Edwards Lifesciences and Medtronic for speaker and consulting activity performed by Dr Chikwe. All other authors have nothing to disclose with regard to commercial support.

Received for publication Dec 23, 2019; revisions received Dec 23, 2019; accepted for publication Dec 25, 2019; available ahead of print March 27, 2020.

Address for reprints: Joanna Chikwe, MD, FRCS, Department of Cardiac Surgery, Smidt Heart Institute, Cedars-Sinai Medical Center, 8700 Beverly Boulevard, Beverly Hills, Los Angeles, CA 90048 (E-mail: Joanna.chikwe@ cshs.org).

J Thorac Cardiovasc Surg 2021;161:94-5

0022-5223/\$36.00

Copyright (c) 2020 by The American Association for Thoracic Surgery

https://doi.org/10.1016/j.jtcvs.2019.12.133
}

Check for updates

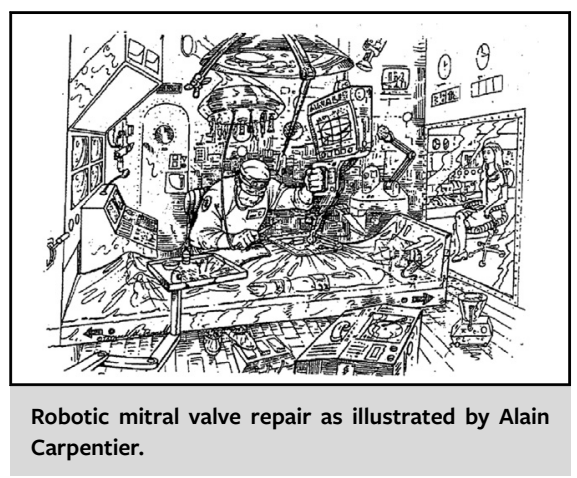

CENTRAL MESSAGE

Robotic mitral repair is repro-

ducible, safe, and effective, but

requires great care when navi-

gating the learning curve.

largely successfully, with an aggressive strategy involving resections that necessitated atrioventricular groove repair in one-third of cases. Their findings demonstrate that MAC is common in patients with degenerative mitral regurgitation, significantly increases operative risk, and that 